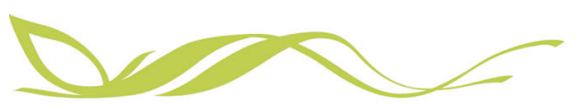

COMMUNICATIONS

EARTH\&ENMRONMENT

ARTICLE

https://doi.org/10.1038/s43247-020-0008-8

OPEN

\title{
Increase in sea level variability with ocean warming associated with the nonlinear thermal expansion of seawater
}

Matthew J. Widlansky (10 ${ }^{1 凶}$, Xiaoyu Long $^{1} \&$ Fabian Schloesser $\mathbb{B}^{1}$

Sea level variability increasingly contributes to coastal flooding and erosion as global sea levels rise, partly due to the thermal expansion of seawater, which accelerates with increasing temperature. Climate model simulations with increasing greenhouse gas emissions suggest that future sea level variability, such as the annual and interannual oscillations that alter local astronomical tidal cycles and contribute to coastal impacts, will also increase in many regions. Here, we present an analysis of the CMIP5 climate model projections of future sea level to show that there is a tendency for a near-global increase in sea level variability with continued warming that is robust across models, regardless of whether ocean temperature variability increases. Specifically, for an upper-ocean warming by $2{ }^{\circ} \mathrm{C}$, which is likely to be reached by the end of this century, sea level variability increases by 4 to $10 \%$ globally on seasonal-to-interannual timescales because of the nonlinear thermal expansion of seawater. As the oceans continue to warm, future ocean temperature oscillations will cause increasingly larger buoyancy-related sea level fluctuations that may alter coastal risks.

\footnotetext{
${ }^{1}$ Joint Institute for Marine and Atmospheric Research, School of Ocean and Earth Science and Technology, University of Hawai'i at Mānoa, 1000 Pope Road, Honolulu, HI 96822, USA. ${ }^{凶}$ email: mwidlans@hawaii.edu
} 
$\mathrm{G}$ lobal sea levels are rising ${ }^{1}$ in part due to the expansion of seawater with increasing temperatures ${ }^{2,3}$. Since the rate, or coefficient, of thermal expansion increases with greenhouse warming 4,5 , seawater density becomes increasingly sensitive to higher temperatures; thereby contributing to observed and future projections of accelerating sea level rise ${ }^{1,6,7}$. So far unexplored is how the nonlinear thermal expansion property of seawater will affect the variability of future higher sea levels.

Variations in coastal sea levels are already causing more frequent flooding and erosion due to increasing sea level rise ${ }^{8-10}$. Regionally, and on seasonal-to-interannual timescales, the sea level variability is mostly determined by the ocean temperature structure, and hence the densities in the seawater column below ${ }^{11,12}$. Large regional sea level variations, such as those associated with the El Niño-Southern Oscillation (ENSO; refs. ${ }^{13-15}$ ), are linked to wind-driven shifts of the thermocline ${ }^{16}$ as well as the oceanic mixed-layer heat content ${ }^{17}$. Many climate models project increased future ocean temperature variability related to more extreme and frequent ENSO events ${ }^{18-20}$. As a consequence, temperature-driven sea level variability (i.e., the thermosteric component ${ }^{21}$ ) also increases in the tropical Pacific Ocean ${ }^{22,23}$.

Given the increase in the rate of thermal expansion with temperature ${ }^{4}$ and the often dominant role of the thermosteric component in explaining sea level variability $11,12,24$, we hypothesize that sea level variability must increase relative to temperature variability in a warming ocean. Combining the effect of nonlinear thermal expansion with increasing temperature variability, e.g., projected in ENSO-affected areas, the increase in sea level variability must then be even larger than that in temperature variability.

Here, we use an ensemble of climate models to show that there is a near-global tendency for the sea level variability to increase with greenhouse warming. We quantify across these models the components of sea level variability change related to either changes in mean temperature (i.e., the change in the rate of thermal expansion) or changes in temperature variability. Thereby, we assess the inter-model uncertainty of future sea level variability associated with these two components. To explain our methodology, we first discuss the oceanic changes near a sample of coastal cities, then expand our analysis globally. The interpretation of results is supported by analytical solutions to a reduced-gravity ocean model prescribed with thermal expansion characteristics from the climate models. Lastly, we discuss implications for describing future coastal flooding and erosion risks.

\section{Results}

Changing sea level variability. Observed sea levels vary seasonally and interannually everywhere, although there are pronounced gradients between regions of larger and smaller variability in sea surface height (SSH; Fig. 1a, b). Some of the largest annual ranges of sea level $(10 \mathrm{~cm}$ to greater than $30 \mathrm{~cm}$ from the minimum to maximum of monthly averages) occur near the continental margins of the northwestern Atlantic and Pacific Oceans, as well as in the northern Indian and the tropical Pacific Oceans (Fig. 1a). For example, in the Florida Strait near the City of Miami, the sea level annual range averages $13 \mathrm{~cm}$ (Fig. 2a; $22 \mathrm{~cm}$ at the local tide gauge). The annual maximum of sea level, which typically occurs during September-November in Miami, often determines the season of greatest risk for coastal flooding 25 . Whereas the sea level annual cycle is incorporated into most tidal predictions ${ }^{26}$, interannual variability (Figs. $1 \mathrm{~b}$ and $2 \mathrm{a}$ ) that either amplifies or dampens the annual cycle ${ }^{27}$, is not. Should interannual high sea level anomalies (Fig. 1b; e.g., standard deviations greater than $5 \mathrm{~cm}$ ) occur during the season of highest sea levels, then coastal flooding is more likely to occur; especially if accompanied by large astronomical tides or exacerbating meteorological events ${ }^{28}$ (e.g., storm surges or runoffs from heavy rainfall).

Global climate models are able to simulate many of the salient features of the observed sea level annual range (Supplementary Fig. 1) and interannual standard deviation (Supplementary Fig. 2), although with somewhat reduced amplitudes. With unabated greenhouse warming (see Methods for discussion of the RCP 8.5
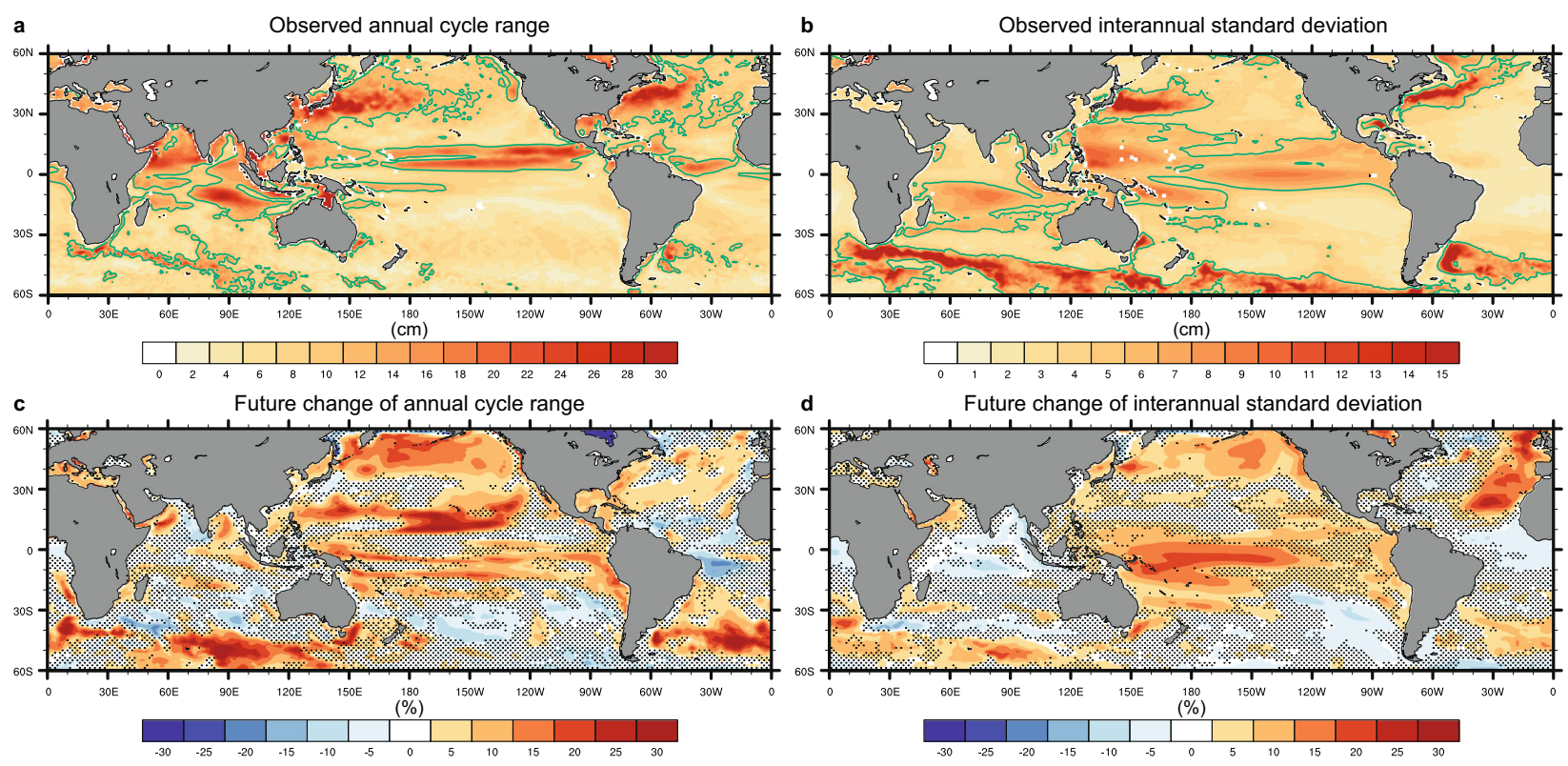

Fig. 1 Observed and projected changes in SSH variability. a, b The observed annual cycle range and interannual standard deviation (cm; shading), respectively from ORA-S5 (Methods). Contours enclose annual ranges and interannual standard deviations greater than $10 \mathrm{~cm}$ and $5 \mathrm{~cm}$, respectively. $\mathbf{c}$, d Multi-model mean (29 CMIP5 models) future projection for RCP8.5 with respect to the historical experiments for the annual cycle range and interannual standard deviation (\% change). Stippling indicates grid points where less than 19 out of 29 models agree on the future change sign for annual cycle and interannual changes. 

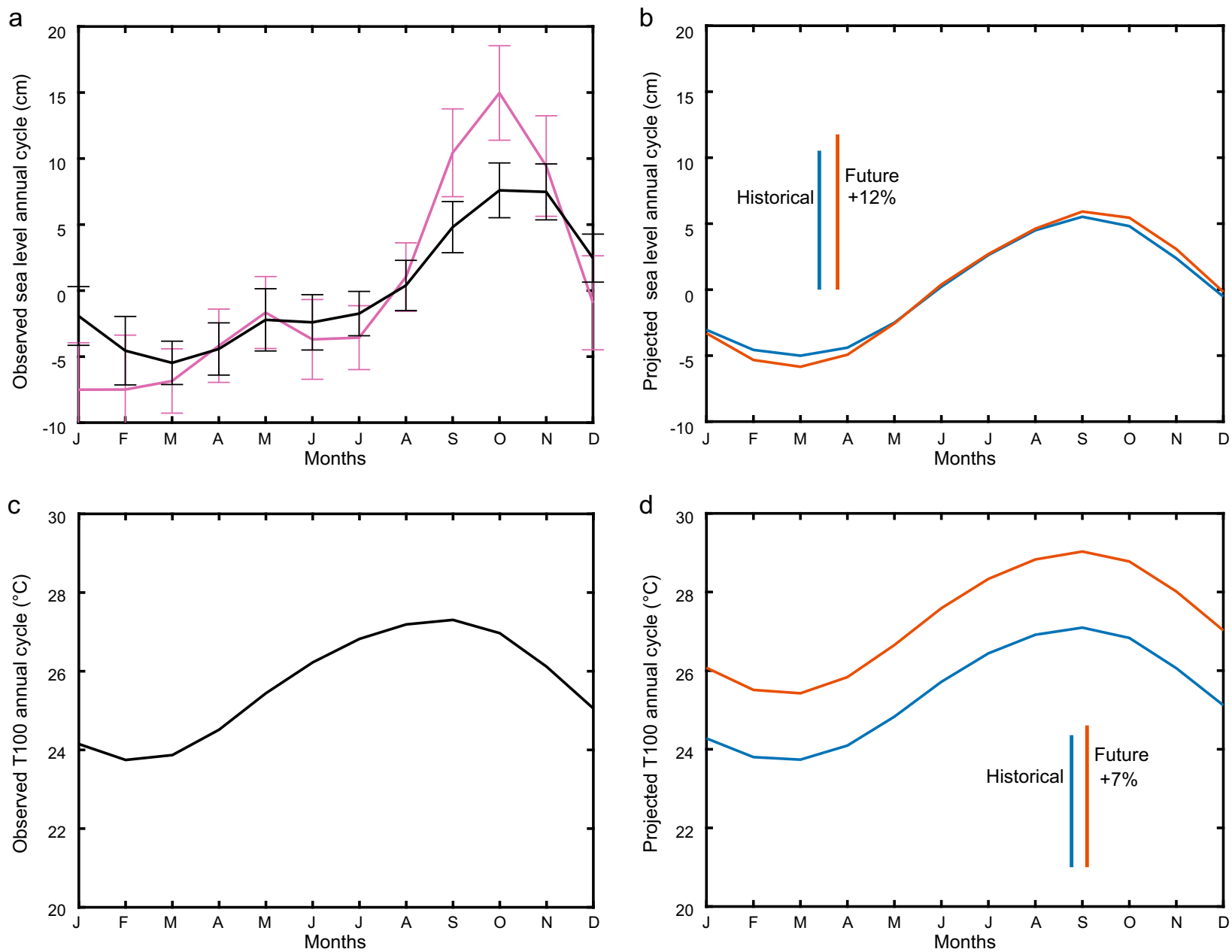

Fig. 2 The annual cycle of sea level $(\mathrm{cm})$ and $\mathrm{T100}\left({ }^{\circ} \mathrm{C}\right)$ around the City of Miami, Florida from observations and the CMIP5 multi-model mean. a, c The sea level and T100 annual cycles, respectively, for ORA-S5 (black) averaged over the $1^{\circ}$ ocean grid box nearest the Virginia Key tide gauge (purple; $25.7^{\circ} \mathrm{N}$, $279.8^{\circ} \mathrm{E}$ ). The seasonally-dependent interannual variability of the tide gauge and ORA-S5 are also shown in (a) (bars; \pm 0.5 standard deviation). $\mathbf{b}$, $\mathbf{d}$ The sea level and T100 annual cycles for the historical (blue) and RCP8.5 (orange) experiments averaged over the nearest $1^{\circ}$ ocean grid to the tide gauge for each model. Sea level annual cycles are normalized to have a mean of zero $(\mathbf{a}, \mathbf{b})$. The vertical lines indicate the magnitude of the annual ranges during the historical and future periods (b, d).

future emissions scenario and CMIP5 climate models), the majority of models that we assessed project increasing sea level variability this century: 28 out of 29 models show increased annual cycle ranges (Supplementary Table 1$)$ in the tropics $\left(30^{\circ} \mathrm{S}-30^{\circ} \mathrm{N}\right)$ as well as the mid-latitudes $\left(30^{\circ}-60^{\circ} \mathrm{N} / \mathrm{S}\right)$; and, the number of models showing increased interannual standard deviations (Supplementary Table 2) are 22 and 26 for the tropics and midlatitudes, respectively. There are stark regional differences in the projected increases of the annual range and interannual standard deviation (Fig. 1c, d), with reduced variability also being projected in some areas. Considered regionally, the inter-model uncertainty of future sea level variability changes is substantial, even concerning the sign of changes (stippling in Fig. 1c, d).

Physical processes. One large region where many models do agree on increasing sea level variability is in the tropical Pacific (interannual standard deviation changes of $20 \%$; Fig. 1d), which has been shown to be related to more frequent occurrences of strong El Niño and La Niña events in the future ${ }^{23}$. Increasing ENSO variability ${ }^{18-20}$ would intensify primarily wind-driven fluctuations of the tropical Pacific thermocline, upper-ocean temperatures, and sea level ${ }^{12,13,29}$.
Yet, the future sea level is projected to become more variable interannually in many regions that are not directly affected by ENSO (Fig. 1d; e.g., in the mid-latitudes). Furthermore, the annual cycle of sea level is also projected to become larger in more areas than not (Fig. 1c), such as near Miami where the range during the 21 st century future simulation is $12 \%$ larger than during the 20 th century historical simulation (Figs. $1 \mathrm{c}$ and $2 \mathrm{~b}$ ). For seasonal-tointerannual variability in many regions, ocean temperature fluctuations will directly affect the sea level due to the sensitivity of seawater buoyancy to temperature (i.e., thermal expansion or contraction of the water column), which is the dominant mode of variability ${ }^{11,12}$ (i.e., sea level can often be substituted by thermosteric sea level; Methods). At Miami, for example, the annual maximum of sea level usually occurs close to when the upper-100 m ocean temperature (T100, which is a proxy for most of the column-integrated temperature variability that typically occurs above the thermocline at this location ${ }^{27}$ ) is the warmest (Fig. 2a, c; October or September peaks). Similar coherence between temperature and sea level cycles ${ }^{11}$ are observed for most coastal regions ${ }^{30,31}$, with wind-driven mass redistributions and other processes explaining differences, especially in shallow seas ${ }^{32}$.

For Miami, the CMIP5 average annual range of T100 is projected to increase by $7 \%$ (Fig. $2 \mathrm{~d}$ ). If the rate of thermal 
expansion was constant (and assuming no changes in mass or salinity), the increased temperature variability would translate into a $7 \%$ increase in sea level variability (Fig. 3a). However, according to the equation of state (EOS; Methods) of seawater ${ }^{33}$,

a

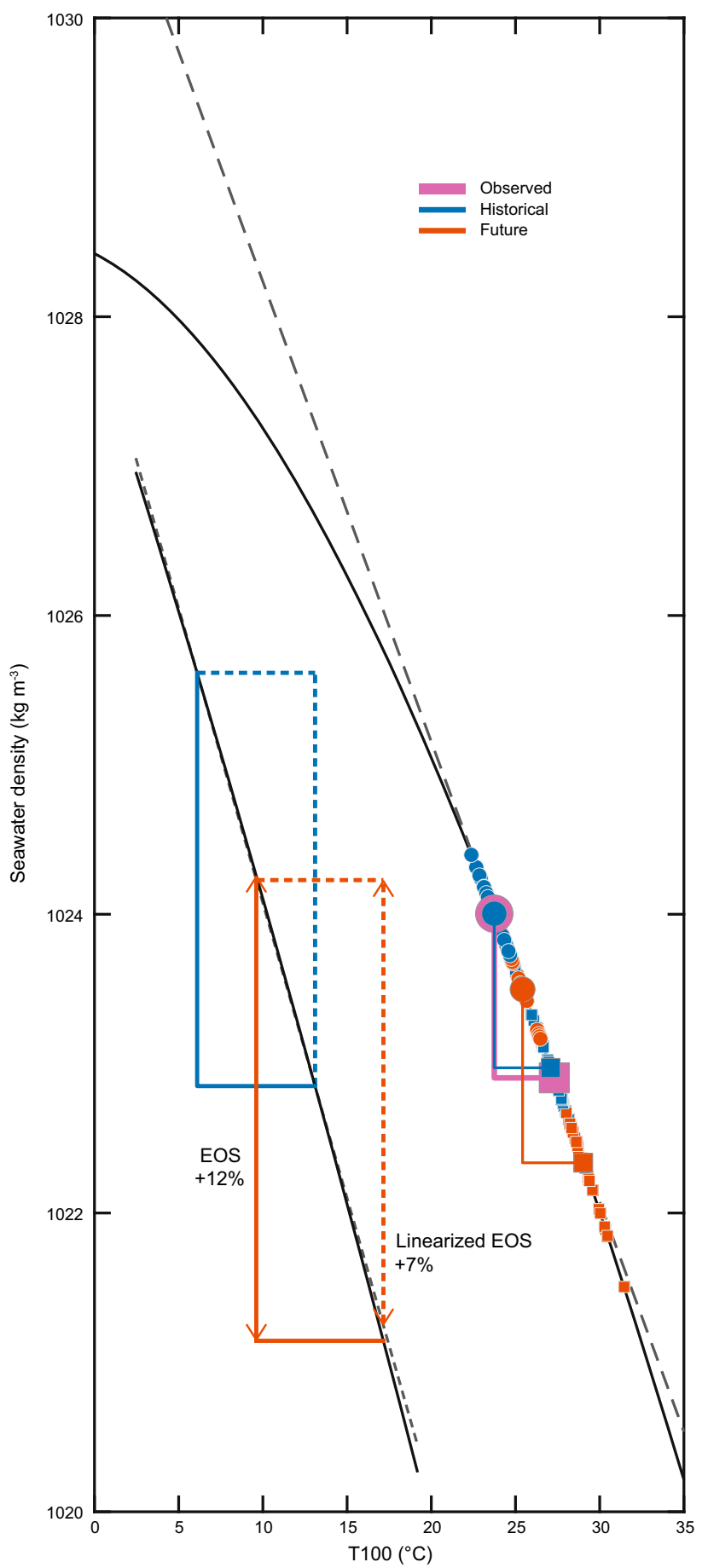

which describes empirically the ocean density as a nonlinear function of temperature, salinity, and pressure ${ }^{34}$, the thermal expansion coefficient increases with ocean temperature. While the EOS is nonlinear in several ways, it is the relation between the

b

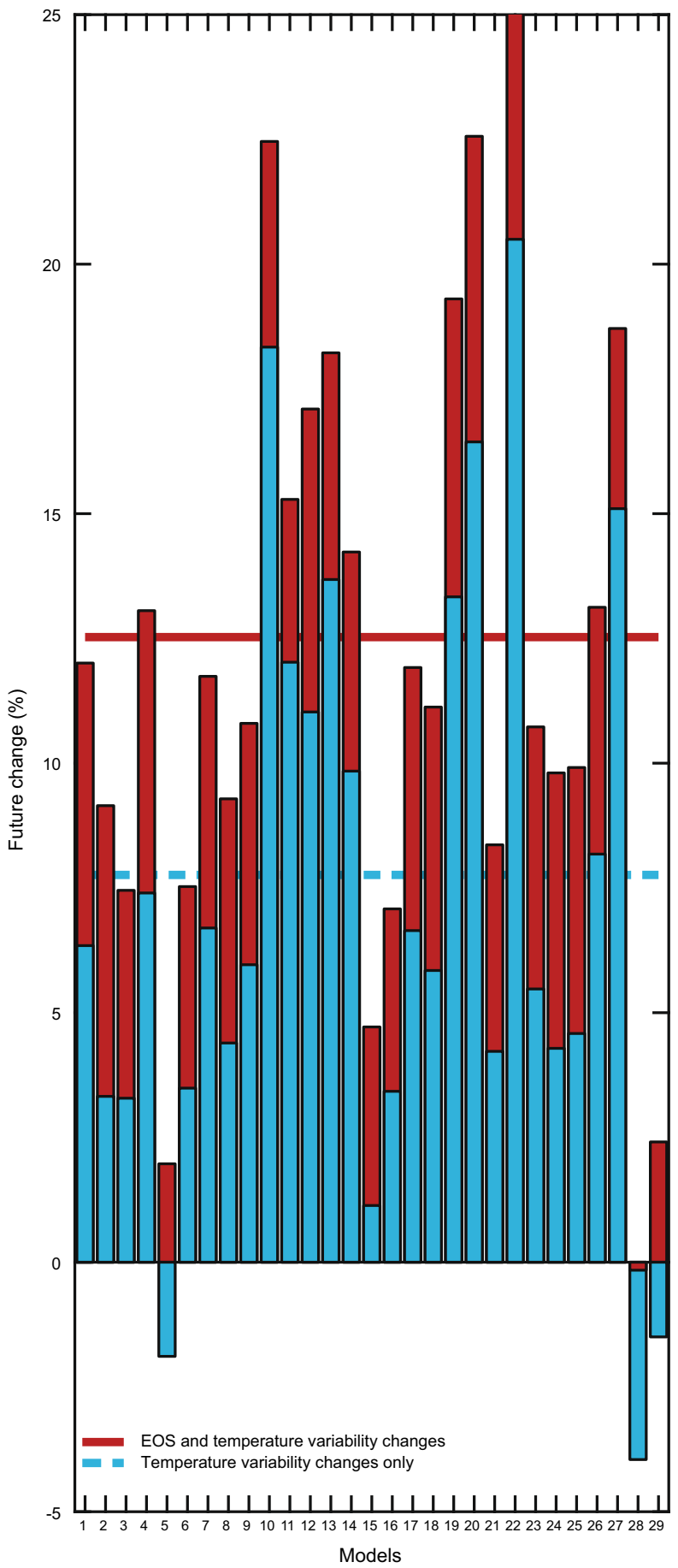

Fig. 3 Seawater density $\left(\mathrm{kg} \mathrm{m}^{-3}\right)$ variability associated with the annual cycle of $\mathrm{T100}\left({ }^{\circ} \mathrm{C}\right)$ around the City of Miami, Florida from observations and CMIP5 models. a The seawater density-temperature relationship (black lines) is shown with ORA-S5 (magenta), historical (blue), and future (orange) projections overlaid. Circles and squares indicate respectively the T100 annual cycle minimum and maximum for each model (smaller shapes) and the multi-model average as well as ORA-S5 (larger shapes). Horizontal and vertical lines indicated the T100 and density ranges, respectively, for ORA-S5 and the multi-model average for the historical and future projections. The insert illustrates the different future increases in density variability expected according to the EOS (solid) and a version of the EOS linearized around the historical T100 range (dashed; i.e., using a constant thermal expansion coefficient). b Future change (RCP8.5 with respect to the historical experiment; \%) of the density annual cycle for each model (bars) and the multi-model average (horizontal lines). Red indicates the total change and blue indicates the component of change associated with temperature variability only. 
thermal expansion coefficient and temperature that is of most interest here. According to this relation, the density (and therefore sea level) range associated with a temperature fluctuation of the same amplitude will always be larger for warmer (e.g., 21 st century) than cooler (e.g., 20th century) mean temperatures, as illustrated in Fig. 3a. Assuming small changes in the thermal expansion coefficient and temperature variability, changes in thermosteric sea level variability can be expanded linearly and are approximately given by the sum of the two contributions (i.e., associated with the EOS and temperature variability; Methods). For example, the future Miami T100 warms by about $2{ }^{\circ} \mathrm{C}$ (Fig. 2d), increasing the coefficient of thermal expansion by about $5 \%$ (Fig. 3a). Together, the change in annual temperature range $(7 \%)$ and rate of thermal expansion add up to a $12 \%$ increase in thermosteric sea level variability, which matches the local CMIP5 increase in sea level variability (Figs. 1c and $2 \mathrm{~b}$ ).

All 29 CMIP5 model projections that we assessed for the Miami example location have larger total future annual ranges of seawater density compared to if only temperature variability changes are considered (Fig. 3b). Consistent results are found near the six largest coastal cities in the world (Supplementary Fig. 3), which together sample seawater density changes through parts of the tropics and mid-latitudes in the Pacific, Indian, and Atlantic Oceans. Whereas the contribution of the EOS is positive and similar in magnitude across models everywhere (because each model projects future warming seawater near Miami as well as Tokyo, Jakarta, Manila, Mumbai, Lagos, and New York City), the inter-model spread of how T100 variability will change is $-4 \%$ to $20 \%$ for Miami (Fig. 3b; $6 \%$ standard deviation) and even larger for most other locations (Supplementary Fig. 3; e.g., $-9 \%$ to $40 \%$ spread with a $10 \%$ standard deviation for New York City). For near these seven example cities (Fig. 3b and Supplementary Fig. 3), the EOS always contributes to increasing sea level variability, which is in contrast to the CMIP5 projection of decreasing T100 variability for three of the cities (Tokyo, Mumbai, and Lagos). Hence, the temperature variability contribution to future sea level variability is much more uncertain compared to the EOS effect, both across models and among the example locations. Yet, there are places where the future sea level variability decreases (Fig. 1c, d), which presumably must match where decreases in temperature variability are larger than the EOS contribution (e.g., near Mumbai and Lagos in the tropical Indian and Atlantic Oceans, respectively; Supplementary Fig. 3).

We globally computed the relative contributions of changes in the rate of thermal expansion (i.e., the EOS) and temperature variability (e.g., associated with the annual cycle or ENSO changes) to thermosteric sea level (Fig. 4). This analysis follows that for Miami and the other large coastal cities used as examples, except that we consider ocean temperature over the full water column (Methods). We also assessed the veracity of the assumption that thermosteric sea level variability is a good proxy for sea level variability by comparing the CMIP5 inferred annual range and interannual standard deviation with the direct model output of SSH (Supplementary Figs. 1, 2), as well as the observed monthly anomalies of thermosteric sea level and SSH (Supplementary Fig. 4). As has been shown previously ${ }^{21,35,36}$, thermosteric sea level and SSH correlate well, although amplitudes deviate in some regions (e.g., the North Atlantic for interannual variability). The mostly larger amplitude of thermosteric sea level variability compared to SSH in CMIP5 (Supplementary Figs. 1,2) is indicative of other processes, such as salinity ${ }^{37}$, also contributing to sea level variability. Since the impact of salinity on ocean stratification tends to increase with latitude ${ }^{38}$, we have restricted the sea level analysis to between $60^{\circ} \mathrm{S}$ and $60^{\circ} \mathrm{N}$. Here, the similarity between thermosteric sea level and SSH, and especially the future changes of each (Supplementary Figs. 1, 2), gives confidence for our approach to determining the components of sea level variability changes.

The future sea level variability changes associated with the EOS (i.e., holding constant ocean temperature variability) are shown in Fig. $4 \mathrm{a}, \mathrm{b}$ (annual range and interannual standard deviation, respectively). As expected for future near-global warming, the change in variability is positive almost everywhere for all models (parts of the equatorial Pacific and North Atlantic are exceptions, which we discuss in the next section). The patterns of variability changes are primarily determined by two factors that are
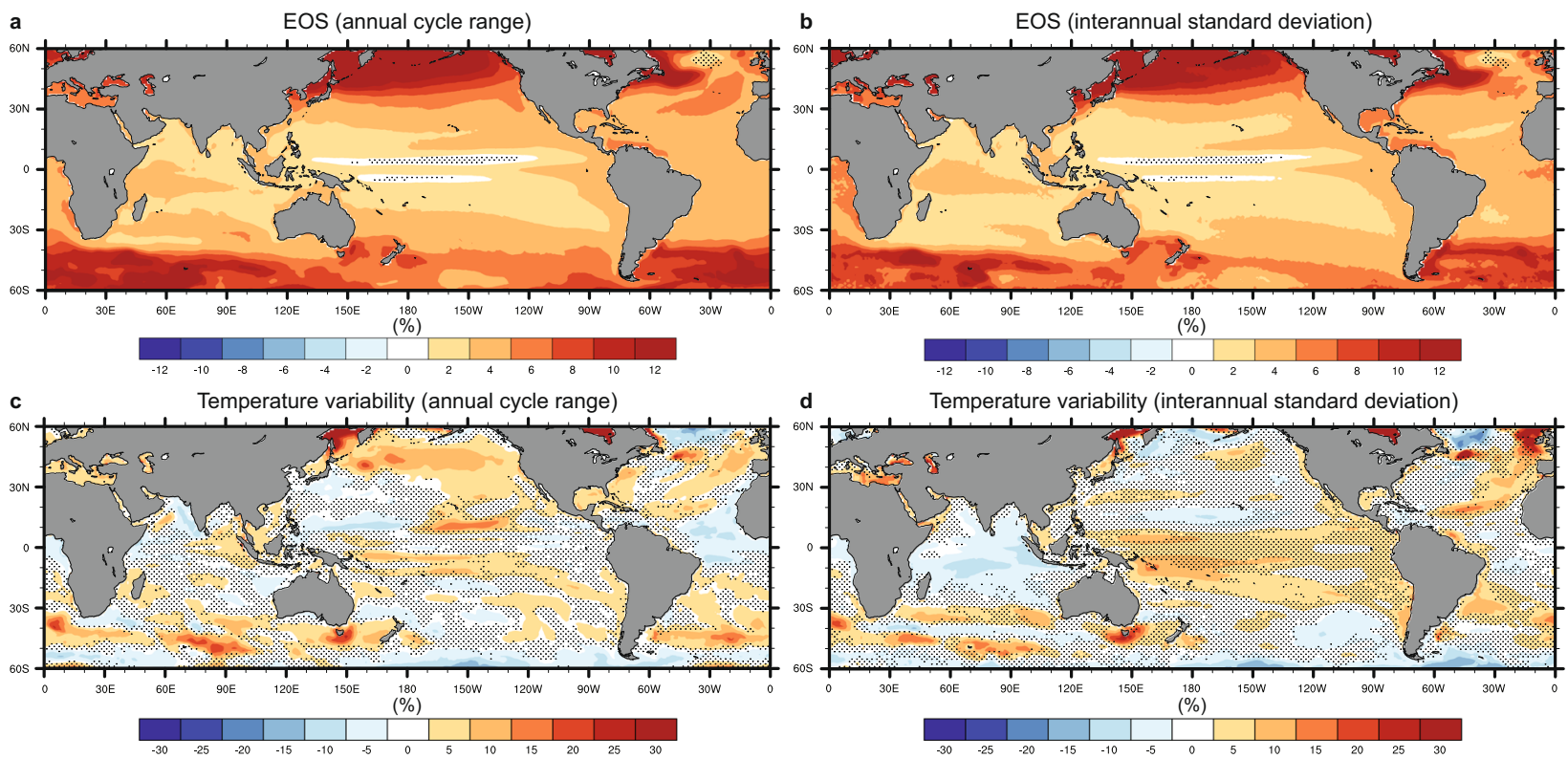

Fig. 4 Components of future projected changes (\%) of CMIP5 multi-model mean SSH. a, $\mathbf{b}$ Changes associated with the seawater EOS of the annual cycle range and interannual standard deviation, respectively. c, d Similar respective changes associated with ocean temperature variability changes. a-d The changes are scaled by dividing each component by the total thermosteric sea level variability during the historical period (see inference calculation in the Methods). Stippling indicates grid points where less than 19 out of 29 models agree on the future change sign. 
illustrated in Fig. 3a: (i) future warming amount (for greater warming, there is a larger difference in the amount of thermal expansion per temperature fluctuation; i.e., the EOS slope increases with increasing temperature) and (ii) historical mean temperature (the rate that thermal expansion increases is less as seawater warms; i.e., the decreasing rate of slope change of the EOS with increasing temperature). Combining these factors, for both annual and interannual timescales of variability (Fig. 4a, b), the future sea level changes are largest at higher latitudes $(>12 \%$, except in parts of the North Atlantic and the South Pacific) and smallest in the tropics (0-4\%). The greater changes in the higher latitudes compared to the tropics for variability associated with the EOS (e.g., New York City versus Jakarta; Supplementary Fig. 3) are expected considering that, in the former region, the future warming is projected to extend to greater depths (factor $i$; Supplementary Figs. 5,6) and historical mean temperatures are relatively cooler (factor ii).

Inter-model consensus and uncertainty. Unlike the almost certain likelihood that future ocean mean temperatures will be warmer nearly everywhere, for many regions there is inter-model uncertainty whether temperature variability will increase or decrease $\mathrm{e}^{5,39,40}$. Considering the sea level response to changes in the annual range of ocean temperatures (Fig. 4c), there are only a few regions of multi-model agreement that the future variability will increase (29\% area between $60^{\circ} \mathrm{N} / \mathrm{S}$, which is not stippled) and be of much larger magnitude than the change expected from the EOS (e.g., part of the tropical Pacific south of Hawaii). Around Miami, the effect on sea level of increasing temperature annual range $(5 \%)$ is comparable to that expected from the EOS. For the interannual variability, inter-model consensus is also weak that future ocean temperature fluctuations will increase in most locations (Fig. $4 \mathrm{~d}$; only $14 \%$ of the global area). Although, the tropical southwestern Pacific is a notable exception where more than $2 / 3$ models agree on increased temperature-sea level variability, which is associated with future ENSO changes ${ }^{23}$. In general, where there is inter-model consensus of increasing ocean temperature annual and interannual variability (Fig. $4 \mathrm{c}, \mathrm{d}$ ), such as in the tropical Pacific, the CMIP5 projected change in SSH variability is especially large and consistent across models (Fig. 1c, d).

In a future warming environment, there is robust inter-model agreement of increasing sea level variability associated with the EOS that will almost certainly affect the annual cycle range and interannual standard deviation throughout most of the tropics and mid-latitudes (Fig. 4a, b and Supplementary Tables 1, 2). The only regions where some models project smaller future sea level variability related to the EOS are in parts of the equatorial Pacific and the high-latitude North Atlantic (stippling in Fig. 4a, b). Depth profiles of the ocean temperature variability and future warming for regions of reduced future sea level variability associated with the EOS reveal that some models do project future cooling at certain ocean levels, including where temperature variability is large (Supplementary Figs. 5, 6). As the total change in thermal expansion rate is a vertical average weighted by the amount of temperature variability (Methods), the EOS component of sea level variability change can be negative (i.e., an opposite thermodynamic change to that illustrated in Fig. 3a) under such conditions even if the (unweighted) depth-averaged temperature increases. One such example is future cooling near the thermocline of the equatorial western Pacific, which increases the regional upper-ocean stratification (Supplementary Fig. 7) more than if only near-surface warming were to occur ${ }^{38}$.

We have considered so far the components of future sea level variability changes under the inference that sea level variations are fully explained by the ocean temperature and density characteristics (i.e., sea levels determined solely by the EOS and temperature variability). It is informative to compare these results with the sea level variability changes projected by CMIP5; the multi-model mean of which (Fig. 1c, d) we discussed previously. Figure 5 relates, model-by-model, the CMIP5 output of SSH variability change ( $y$-axes) to the component of change associated with either the EOS or temperature variability ( $x$-axes). For both annual and interannual timescales, the multi-model mean changes associated with the EOS are closely aligned with the SSH multi-model mean changes in the tropics and mid-latitudes (Fig. 5a, b). Whereas the inter-model spreads of the temperature variability components explain much of the uncertainty of $\mathrm{SSH}$ projections (Fig. 5c, d), in a multi-model mean sense, less than half of the SSH changes are explained by temperature variability. In fact, the inter-model spread of the change of interannual temperature variability (Fig. $5 \mathrm{~d}$; e.g., $-7.2 \%$ to $11.7 \%$ in the tropics; see Supplementary Tables 1, 2 for model-by-model statistics) suggests that this is the most uncertain of the sea level change components that we considered.

The proportion of increasing SSH variability associated with the EOS depends on the amount of future ocean heat uptake. For upper-ocean warming that is likely to occur in most of the tropics and mid-latitudes by the end of this century (e.g., regionalaverage T100 warms by $2{ }^{\circ} \mathrm{C}$; Fig. 6 ), the projected increases of the $\mathrm{SSH}$ annual cycles associated with the EOS are $4 \%$ (tropics; Fig. 6a) and 10\% (mid-latitudes; Fig. 6b). Since we are assessing the projected changes with respect to the amount of future warming, these increases are relative to the latter part of the historical simulation (Methods), rather than the entire 20th century (e.g., as in Fig. 5). EOS contributions to increases of the $\mathrm{SSH}$ interannual variability, for $2{ }^{\circ} \mathrm{C}$ warming, are similar $(4 \%$ and $8 \%$ in the tropics and mid-latitudes, respectively; Fig. $6 \mathrm{c}, \mathrm{d}$ ). Even larger SSH annual cycle and interannual variability changes associated with the EOS are expected for greater warming (e.g., $2.5^{\circ} \mathrm{C}$; Fig. 6). In contrast, the temperature variability changes are smaller and much more uncertain (especially interannual variability) for all future warming amounts expected anytime this century (Fig. 6). In fact, for the majority of models that simulate at least $2{ }^{\circ} \mathrm{C}$ of $\mathrm{T} 100$ warming in the tropics and midlatitudes, there is no multi-model consensus that interannual temperature variability will increase; yet, the $\mathrm{SSH}$ variability increases in most of these same models (Fig. 6c, d).

Interpretation. Overall, for the CMIP5 climate models and RCP8.5 greenhouse warming scenario that we considered, it is perceivable that the annual cycle and interannual variability of sea level will both increase at many coastal locations. Such a tendency exists, at least in part, because the thermal expansion rate of seawater increases with warming (i.e., the EOS nonlinearity), which inherently causes density-related sea level variability to also increase even if the temperature variability itself does not change. Furthermore, the CMIP5 SSH projection is characterized by large inter-model spread in many regions (Fig. 1c, d) that is primarily related to uncertainty across models in how future ocean temperature variability will respond to continued greenhouse warming (Figs. 4c, d, 5c, d and 6).

Whereas our CMIP5 analysis supports the hypothesis that seasonal-to-interannual sea level variability will increase relative to changes in ocean temperature variability due to nonlinearity of the EOS, the EOS alone does not constrain future sea level variability to increase in a warming ocean. From this perspective, future sea level variability could also remain constant with reduced temperature variability. Indeed, CMIP5 models diverge substantially in the projected amount of sea level variability increase because of the uncertainty in ocean temperature 

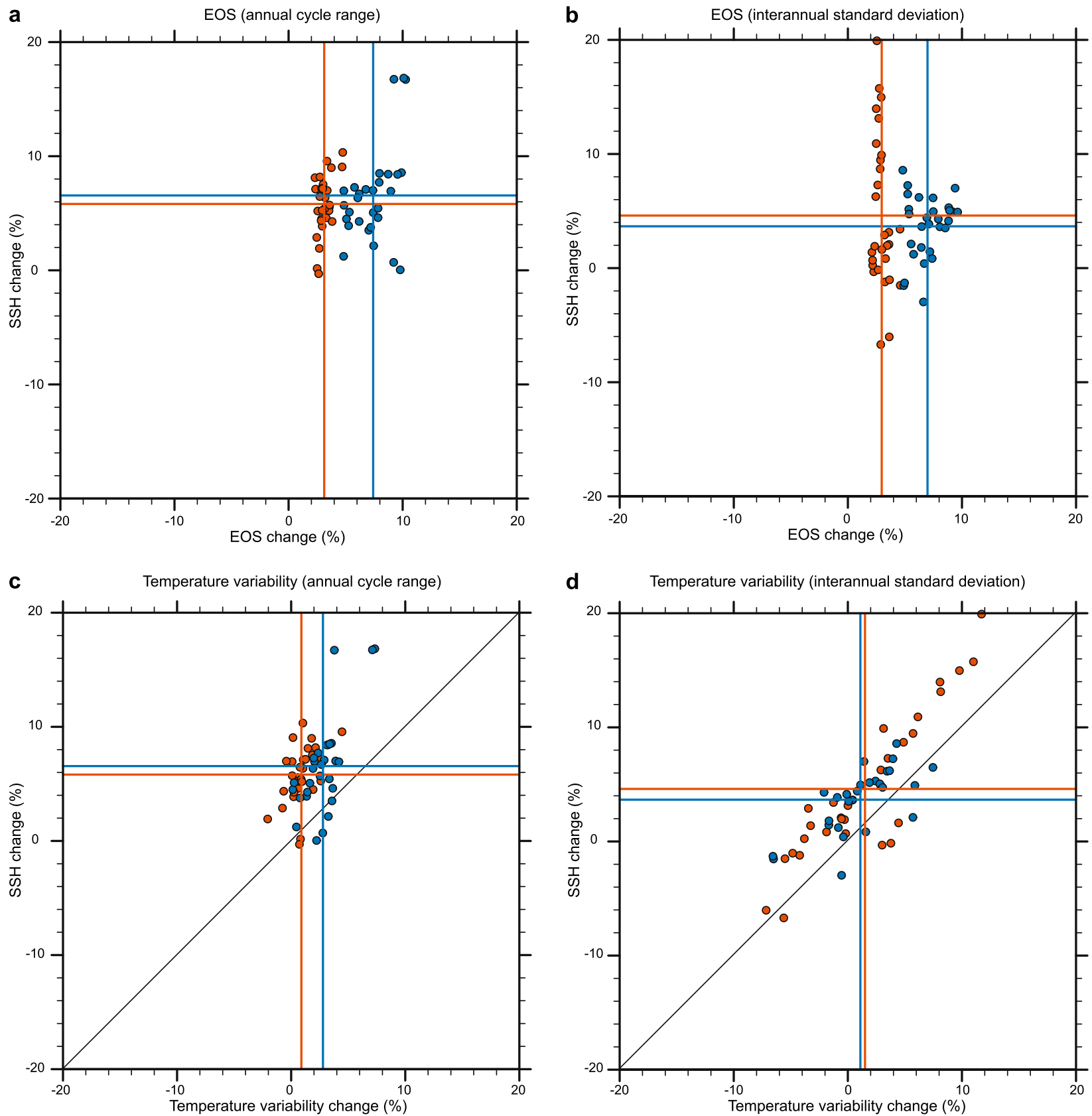

Fig. 5 Inter-model spread of future projected changes (\%) of CMIP5 SSH related to the seawater EOS and ocean temperature variability. a, b Changes associated with the EOS of the annual cycle range and interannual standard deviation, respectively. c, $\mathbf{d}$ Similar respective changes associated with temperature variability. The distance of a point from the diagonal line is indicative of the change in SSH variability relative to temperature variability. a-d Changes are colored by latitude range $\left(30^{\circ} \mathrm{S}-30^{\circ} \mathrm{N}\right.$ : orange; $30^{\circ}-60^{\circ} \mathrm{N} / \mathrm{S}$ : blue). The multi-model mean changes for each region are indicated by the vertical and horizontal lines. Changes associated with the EOS and temperature variability components ( $x$-axes) are scaled similarly to Fig. 4 . Changes of sea level variability ( $y$-axes) are for the CMIP5 SSH variable from the RCP8.5 experiment with respect to the historical experiment.

variability changes (respectively, stippling in Figs. 1c, $d$ and $4 c$, d; see also shading in Fig. 6). Certainly also contributing to future sea level and temperature variability changes in CMIP5 are changes in the variability of atmospheric forcing. Because such forcing impacts variability in the oceans locally as well as globally, the effects of atmospheric changes are difficult to separate from those of increased oceanic thermal expansion and stratification in coupled climate model simulations. For this reason, we consider how thermal expansion and stratification impact sea level and thermocline variability (a proxy for temperature variability) in an analytic, reduced-gravity ocean model prescribed with future warming but otherwise unchanged atmospheric forcing.
We obtain analytic model solutions to periodic heat or wind forcings (Cases 1 and 2, respectively; Methods) in an idealized domain representing the subtropical gyre of the North Pacific during historical (cool) and future (warm) climate conditions. Overall, for the CMIP5 projected thermal expansion and ocean stratification increases in the subtropical North Pacific (Fig. 4a and Supplementary Fig. 7, respectively), sea level variability tends to increase, and thermocline variability to decrease, in spite of no change in atmospheric forcing between the historical and future solutions (Fig. 7). For the heat-forcing experiment (i.e., Case 1; Fig. 7a), sea level variability increases proportionally to the prescribed thermal expansion coefficient change, which 
a

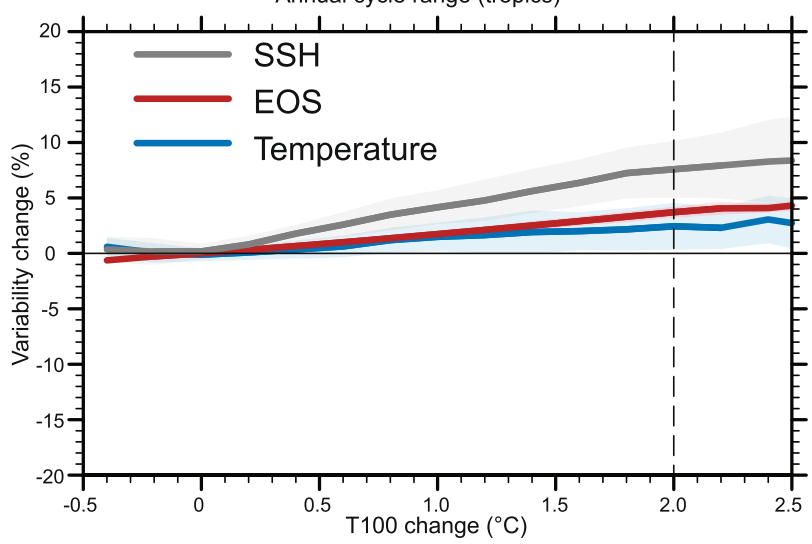

C

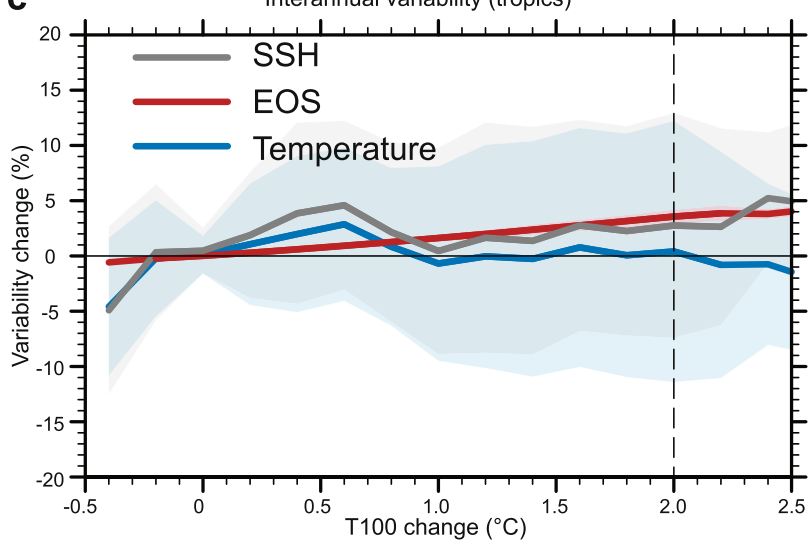

b

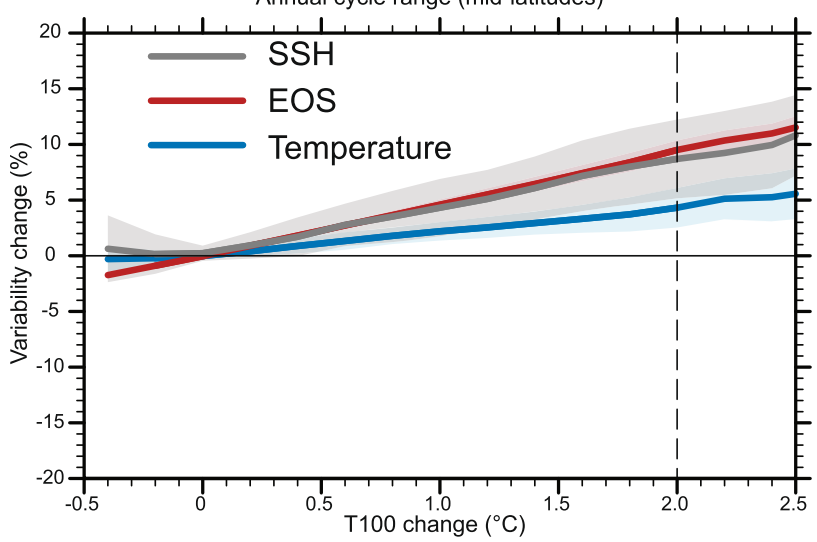

d

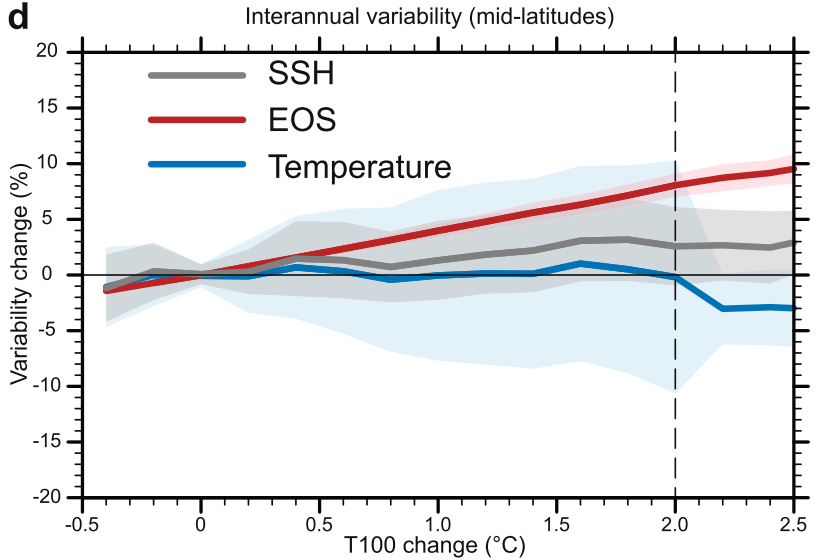

Fig. 6 CMIP5 projected changes of the SSH, EOS, and temperature variability with respect to the projected warming in T100 ( $\left.{ }^{\circ} \mathrm{C}\right)$. a, b Annual cycle range for the tropics and mid-latitudes, respectively. c, d Same but for interannual variability. Changes are calculated over 30-year running windows, started every 5 years from 1906-2100, relative to the 30-year climatology at the end of the historical experiment (1976-2005). Solid lines indicate the multi-model averages for each $0.2^{\circ} \mathrm{C}$ bin of temperature change. The shadings indicate uncertainty $\left( \pm 1\right.$ standard deviation) across the models. For $2{ }^{\circ} \mathrm{C}$ warming (vertical lines), which occurs in 26 out of 29 models by 2100 in the tropics, the annual cycle changes (a) are $8 \%$ (SSH), 4\% (EOS), and 2\% (temperature). The respective changes in the mid-latitudes (21 models; b) are $9 \%(\mathrm{SSH}), 10 \%$ (EOS), and $4 \%$ (temperature). The interannual variability changes for $2{ }^{\circ} \mathrm{C}$ warming are, for the tropics (c), 3\% (SSH), 4\% (EOS), and $0 \%$ (temperature) and, for the mid-latitudes (d), 3\% (SSH), $8 \%(E O S)$, and $0 \%$ (temperature).
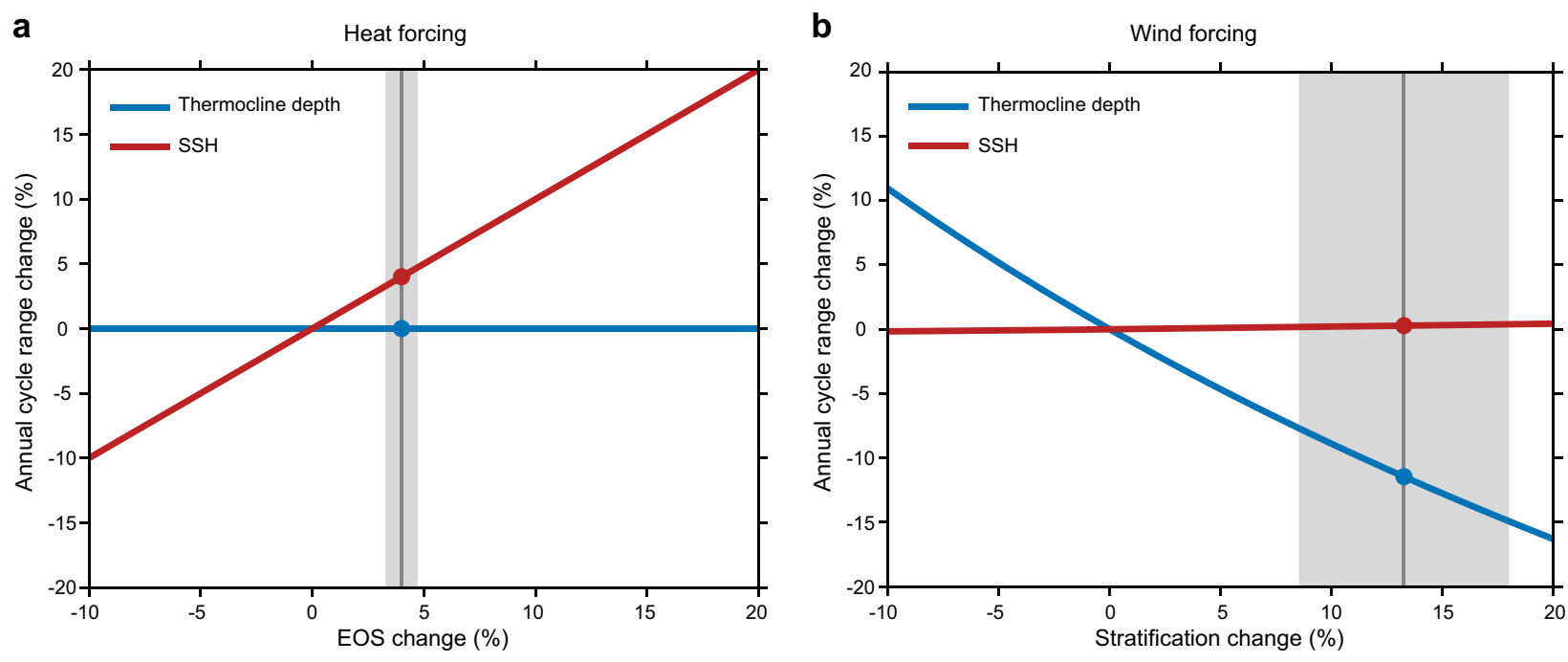

Fig. 7 With constant annual cycle forcing of heat (a) or wind (b), future change of the annual cycle ranges ( $y$-axes; \%) of SSH (red) and thermocline depth (blue) from analytical solutions to various changes in the seawater EOS or ocean stratification ( $x$-axes; \%). CMIP5 future projected changes of the EOS (a) or stratification (b) in the subtropical region of the North Pacific $\left(15^{\circ} \mathrm{N}-35^{\circ} \mathrm{N}, 140^{\circ} \mathrm{E}-120^{\circ} \mathrm{W}\right.$ domain averages of Fig. $4 \mathrm{a}$ and Supplementary Fig. 7, respectively) are indicated by the vertical lines (multi-model mean) and shading (inter-model spread, \pm 1 standard deviation). The latitude-longitude varying solutions corresponding to the domain averages in (b) (wind forcing experiment) are shown in Supplementary Fig. 8. 
determines how much the surface-layer thickness varies in response to the unaltered variability of heating. For the windforcing experiment (i.e., Case 2; Fig. 7b), assuming that the forcing period is sufficiently long such that Rossby wave adjustments redistribute mass and heat throughout the basin (i.e., the circulation remains near equilibrium ${ }^{41}$ ), sea level variability is insensitive to changing ocean stratification. (Note that increasing stratification is only partly due to the EOS effect on buoyancy, but also to the ocean warming and thus expanding faster near the surface than at depth ${ }^{38}$, e.g., Supplementary Fig. 5.) Since Sverdrup transports are not affected by stratification $^{41}$, and with no periodic heating to affect the surface-layer thickness, the sea level gradients in the gyre will only adjust to the wind forcing, which in this experiment vary the same in both climate conditions. Even though the periodic wind forcing is unchanged, thermocline variability is reduced with increasing stratification (Fig. 7b), because of decreasing thermocline slopes (Supplementary Fig. 8), implying reduced redistribution of heat (i.e., less temperature variability) in the future.

Larger sea level variability due to increased thermal expansion, combined with unchanged sea level variability due to increased ocean stratification (despite reduced temperature variability), in the analytic model (Fig. 7a, b and Supplementary Fig. 8) suggests that the EOS will on average contribute to increasing sea level variability in the future, both relative to any change in temperature variability and in absolute terms. The same thermodynamic constraints imposed by the EOS presumably hold in a cold climate as well (i.e., decreased thermal expansion and stratification; Fig. 7a, b). Consequently, reduced thermosteric sea level variability and enhanced thermocline variability would be expected during glacial periods.

Although future thermocline variability is reduced in the analytic model when ocean stratification increases (Fig. 7b), there is no wide-spread projected decrease of temperature variability in CMIP5 in the subtropical North Pacific or elsewhere (Fig. 4c, d). This is suggestive of stronger atmospheric forcing in the future (e.g., associated with increasing ENSO variability ${ }^{18-20}$ ) balancing such tendencies on the thermocline, as well as contributing to projected sea level variability increases beyond that explained by increasing thermal expansion (Fig. 7a).

\section{Discussion}

In summary, the thermal expansion property of seawater, which is described by the nonlinear characteristic of the EOS, contributes to a global-scale tendency for the sea level to become more variable relative to temperature fluctuations with continued greenhouse warming. Such a tendency, which would alter the risks of coastal flooding and erosion beyond changes associated with anticipated accelerating sea level rise ${ }^{10}$, exists regardless of whether or not the ocean temperature variability increases in the future. An inference from these results is that the inter-model uncertainty of CMIP5 projected changes in SSH variability is explained in most regions by the uncertainty of future ocean temperature variability. A way forward to better describing coastal risks related to sea level variability is therefore either to reduce the uncertainty of how ocean temperature variability will change or, if that is not possible, to make assumptions based on the tendency for increasing sea level variability caused by the nonlinear thermal expansion of seawater.

\section{Methods}

Observations and reanalysis products. To describe the observed SSH and threedimensional ocean temperature, we used the ECMWF Ocean Reanalysis-System 5 (ORA-S5; ref. ${ }^{42}$ ). We performed analyses on a globally uniform $1^{\circ}$ latitude $\times 1^{\circ}$ longitude grid between $60^{\circ} \mathrm{S}-60^{\circ} \mathrm{N}$ to encompass a large portion of the world's oceans, yet limiting the area covered by sea ice. During the 1993-2018 period that we analyzed, ORA-S5 assimilated satellite altimetry measurements of SSH along with observed depth profiles of ocean temperature and salinity. We compared the SSH from ORA-S5 for an example region around Miami, Florida with the nearby Virginia Key shore-based tide gauge record (1994-2018; Fig. 2a), which we acquired from the Quality Assessment of Sea Level Data archive ${ }^{43}$.

For all variables, we calculated the mean annual cycle and monthly mean anomalies with respect to the observed period. We also subtracted the locationspecific linear trend for the same period; thus the contribution of recent sea level rise is removed from our assessment of sea level variability (i.e., annual cycle range and interannual standard deviation). For analyses of interannual variability, we lastly high-pass filtered the monthly anomalies to remove any oscillations with periods longer than 11 years. This final step is necessary to distinguish the effect of accelerating ocean heat uptake associated with greenhouse warming from the interannual variability, which is especially important when considering future climate projections on centennial timescales.

CMIP5 projections. We assessed the greenhouse warming projections in 29 coupled ocean-atmosphere climate models from the Coupled Model Intercomparison Project Phase 5 (CMIP5; ref. ${ }^{44}$ ). The model names are listed in Supplementary Table 1 . We assessed one experiment from each model, covering the period 1906-2005 using historical anthropogenic and natural forcings and then the future emission scenario (RCP8.5) for 2006-2100, which ignores volcanic and other natural aerosols. For each model, we first interpolated the dynamic SSH and three-dimensional ocean temperature to the $1^{\circ}$ latitude $\times 1^{\circ}$ longitude grid using bilinear interpolation. We calculated the mean annual cycle for the historical and future periods and then monthly mean anomalies with respect to each period. Following ref. ${ }^{23}$, we derived changes in the variability of SSH and ocean temperature by comparing the first 95 years (1906-2000, historical period) to the later 95 years (2006-2100, future period); thus, there was a large ratio between the climate change signal and any higher-frequency variability internal to the models To assess how the ocean condition varies as a function of the future warming amount (Fig. 6), we compared 30-year running windows starting every 5 years from 1906-2100, with the 30-year climatology from the end of the historical experiment (1976-2005).

In addition to the multi-model mean, we considered the inter-model uncertainty of the projected changes by indicating regions where less than $2 / 3$ of models (i.e., 19 out of 29 models) agree on the future change sign (stippling in Figs. 1c, $d$ and $4 c, d$ ) or showing the inter-model spread (i.e., \pm 1 standard deviation; shading in Fig. 6). We also assessed the projections model-by-model for specific locations, such as near Miami and six of the largest coastal cities in the world, and globally (Figs. 3 and 5; Supplementary Tables 1 and 2; Supplementary Fig. 3). Furthermore, for each model and region (tropics and mid-latitudes), we calculated the percentage area where the sign of projected change disagrees from the multimodel average (Supplementary Tables 1 and 2; i.e., listing the area of decreasing variability)

Empirical EOS to describe seawater density. Seawater density is fully related to its state of temperature, salinity, and pressure (i.e., the EOS). From combining the First and Second Laws of Thermodynamics into the Gibbs function $(G)$, volume $(v)$, and therefore density $(\rho)$, is given by the pressure $(p)$ derivative of $G$ that describes the molecular structure of the substance ${ }^{45}$ (in this case, seawater):

$$
v=\frac{1}{\rho}=\frac{\partial G}{\partial p} .
$$

Since no analytical solution to the EOS exists, empirical expressions based on the measured properties of seawater are used to approximate it in various polynomial forms. We evaluate the density property of seawater using the International Thermodynamic Equation of Seawater-2010 (TEOS-10; ref. ${ }^{33}$ ) and, in particular, the Gibbs Sea Water (GSW) Oceanographic Toolbox of TEOS-10, which uses an expression with 75 coefficients to calculate in situ density as a function of temperature, salinity, and sea pressure ${ }^{46}$. For our calculation of seawater density shown in Fig. 3a, we simplify the EOS by using a reference value for salinity $\left(S, 35.2 \mathrm{~g} \mathrm{~kg}^{-1}\right)$ and considering the sea pressure at 50-m depth (60.4647 dbar).

The sea level nonlinearity ${ }^{4}$ that we explore is explained by the temperature dependence of the thermal expansion coefficient $(\alpha)$, which is the temperature $(T)$ derivative of the EOS with respect to the independent state variables (salinity and pressure) that we hold constant ${ }^{45}$ :

$$
\alpha=-\frac{1}{\rho}\left(\frac{\partial \rho}{\partial T}\right)_{S, p}
$$

Since the thermal expansion coefficient increases with temperature, the change in seawater density and, hence, sea level also increases with temperature. This nonlinear behavior of seawater density is indicated by the changing slope of the EOS (Fig. 3a; i.e., the illustrated response of density to variations in T100). If instead the thermal expansion coefficient did not increase with temperature (e.g., under greenhouse warming conditions), then there would be no acceleration of sea level rise through thermosteric processes ${ }^{4}$. There would also be no increase of sea level variability without a change in temperature variability (i.e., the linearized EOS illustration in Fig. 3a) or some other mechanism that affects sea level (e.g., changes 
in seawater mass). We note that the other derivatives of the EOS (i.e., the coefficients of haline contraction and isothermal compressibility; ref. ${ }^{45}$ ), are not considered in our calculations of seawater density since we use constant reference values of salinity and pressure.

Inference calculation of the components of sea level variability change. The sea level annual cycle and interannual variability are largely explained by ocean temperature variability (i.e., thermosteric sea level, $H_{T}$ ) and the resulting seawater buoyancy changes ${ }^{11,12}$. We therefor infer the thermosteric sea level variability $\left(\delta H_{T}\right)$ based on the ocean density response to temperature changes, which we calculate for each latitude, longitude, and depth between $60^{\circ} \mathrm{S}-60^{\circ} \mathrm{N}$ using the rho_mwif function ${ }^{47}$ of the NCAR Command Language. Similar to our use of the empirical EOS to illustrate the seawater density response to changes in T100 around Miami, Florida (Fig. 3a) and the other example cities (Supplementary Fig. 3), the effect of changing seawater salinity is not considered. Although in our assessments of the full ocean (e.g., Fig. 4a, b), we do adjust for changing depth and pressure (i.e., isothermal compressibility) unlike in (2). Throughout, the effect of mass changes on sea level variability are not considered.

Since changes in the curvature of the EOS are small for ocean temperature fluctuations that are typically observed on seasonal-to-interannual timescales, we approximate the thermosteric sea level variability (e.g., annual cycle range or interannual standard deviation) as

$$
\delta H_{T}=\int_{-D}^{0} \alpha \delta T \mathrm{~d} z
$$

where $\alpha$ is the thermal expansion coefficient and $\delta T$ is the temperature variability (i.e., range or standard deviation) that are each calculated at all ocean depths $(z)$ and integrated from the ocean bottom $(-D)$ to the surface. As in (2), $\alpha$ is representative of the time-mean temperature (i.e., climatology). For future changes of the mean temperature (hence also $\alpha$ ) and $\delta T$ that are small relative to their historical values, we decompose the future change (denoted by $\Delta$ ) in the thermosteric sea level variability using a linear expansion of (3):

$$
\Delta \delta H_{T}=\int_{-D}^{0} \Delta \alpha \delta T_{\text {historical }} \mathrm{d} z+\int_{-D}^{0} \alpha_{\text {historical }} \Delta \delta T \mathrm{~d} z .
$$

On the right-hand side of (4), the first term represents the future change of $\alpha$ that is related to the nonlinearity of the EOS (e.g., Fig. $4 \mathrm{a}, \mathrm{b}$ ), and the second term is due to the future change in temperature variability (e.g., Fig. 4c, d). Specifically, $\Delta \delta H_{T}$ is the future change relative to the historical condition of thermosteric sea level variability (either the annual cycle range or interannual standard deviation; Supplementary Figs. 1,2) that we infer by combining the terms on the right-hand side of (4): $\alpha_{\text {historical }}$ and $\Delta \alpha$ are respectively the historical mean and future change of the thermal expansion coefficient, and the temporal distinction is similar for temperature variability $\left(\delta T_{\text {historical }}\right.$ and $\left.\Delta \delta T\right)$.

Through comparisons of the observed SSH (i.e., ORA-S5) and inferred sea level (i.e., Eq. 4) characteristics, using calculations of the anomaly correlation coefficients at each grid location (Supplementary Fig. 4), we determined that the inference method resolves most of the annual cycle and interannual variability (in $83 \%$ and $77 \%$ of the area, respectively). The comparison is especially close for the annual cycle range almost globally and the interannual standard deviation in the tropical Pacific. The patterns of root mean square errors mostly mirrors the correlations (Supplementary Fig. 4).

As we noted, the inferred sea level variability that we calculate is larger than the direct CMIP5 output of SSH almost everywhere (Supplementary Figs. 1, 2 show maps of the comparison of annual cycle range and interannual standard deviation, respectively, for the historical and future periods). Such a result is to be expected, as there are contributions to sea level variability other than temperature (e.g., salinity) that may compensate the effect of temperature variability on the ocean density ${ }^{37}$. Yet, comparing the future change of sea level variability from CMIP5 and using the inference method shows similar patterns for both the annual cycle and interannual standard deviation (Supplementary Figs. 1, 2). Since we consider only future changes in our decomposition of the sea level variability associated with the EOS and temperature variability (Figs. 4-6, Supplementary Tables 1,2), the robustness the total future change patterns gives confidence in the method.

\section{Analytical determination of the sea level variability response to future}

warming. To illustrate sensitivities of the ocean response to changing mean temperature when the atmospheric forcing (i.e., variability of heat or momentum fluxes) is not changed, we present two solutions to a reduced-gravity ocean model ${ }^{48,49}$. In each case, the analytic model is driven by periodic surface fluxes. Specifically, we analyze how the SSH and thermocline variability (a proxy for temperature variability) each change as a function of changes in the mean thermal expansion coefficient and ocean stratification. Solutions are obtained in an idealized oceanic domain resembling the subtropical gyre in the North Pacific (Supplementary Fig. 8); however, the model configuration and experiments are generic enough to make generalizations from the results about the broader oceanic response to future warming (or past cooling) of the climate.

Our analytic model has one active layer with uniformly varying density $\rho_{1}$ at the surface, and an infinitely thick layer below with constant density $\rho_{2}=1,030 \mathrm{~kg} \mathrm{~m}^{-3}$.
Solutions are obtained in a closed ocean basin extending from latitude $y_{\mathrm{s}}=15^{\circ} \mathrm{N}$ in the south to $y_{\mathrm{n}}=35^{\circ} \mathrm{N}$ in the north. Longitudinally, the domain extends from $140^{\circ} \mathrm{E}$ to $120^{\circ} \mathrm{W}$, which, respectively, are the western $\left(x_{\mathrm{w}}\right)$ and eastern boundaries $\left(x_{\mathrm{e}}\right)$. The model is directly forced by Ekman pumping of the form $w_{\mathrm{e} k}=W_{\mathrm{e} k} \sin \left(\frac{y-y_{\mathrm{n}}}{y_{\mathrm{s}}-y_{\mathrm{n}}}\right)$, where the amplitude $W_{e k}$ may depend on time. In steady state, the interior ocean circulation is in Sverdrup balance ${ }^{88,49}$, and the surface-layer thickness is described by

$$
h=\sqrt{h_{e}^{2}-\frac{2 f^{2}}{g^{\prime} \beta} w_{\mathrm{ek}}\left(x_{\mathrm{e}}-x\right)}
$$

where $f$ is the Coriolis frequency, $\beta$ its meridional derivative, and $g^{\prime}=g\left(\rho_{2}-\rho_{1}\right) / \rho_{2}$ is the reduced gravity with the gravitational acceleration being $g=9.81 \mathrm{~m}^{2} \mathrm{~s}^{-1}$. The eastern boundary surface-layer thickness $h_{\mathrm{e}}$ is determined by requiring that the total mass in layer $1, M=\int \rho_{1} h \mathrm{~d} x \mathrm{~d} y=1028 \mathrm{~kg} \mathrm{~m}^{-3} \times 200 \mathrm{~m} \times$ area of the domain, is conserved. Note that infinitesimally thin boundary layers are required to close the circulation, which are assumed to have no further impact on the interior ocean solution ${ }^{49}$. The SSH $(\eta)$ is described by

$$
\eta=\frac{\rho_{2}-\rho_{1}}{\rho_{2}} h+\eta_{o}
$$

relative to a constant level $\eta_{0}$. Note that the model, and the sea level Eq. (6) in particular, imply that barotropic adjustments, which eliminate horizontal pressure gradients in the deep layer, occur instantaneously.

Analytical solutions are compared for a historical and future ocean, with the difference being that the future ocean is more stratified than the historical one due to warming from above and an increased thermal expansion coefficient, which enhances the buoyancy of the upper layer. Specifically, we increase the mean difference between deep- and surface-layer densities (i.e., $\rho_{2}-\rho_{1}$ ) from $2 \mathrm{~kg} \mathrm{~m}^{-3}$ in historical solutions by a range from $-10 \%$ to $20 \%$ in the future simulations, with $13.3 \%$ being the average CMIP5 stratification increase in the subtropical North Pacific region that we are modeling (Supplementary Fig. 8). Stratification changes in CMIP5 models are calculated following the methodology of ref. ${ }^{38}$ as the density difference between $200 \mathrm{~m}$ and the surface (Supplementary Fig. 7).

Case 1, oscillating heat forcing: first, we consider a solution without wind forcing $\left(W_{\mathrm{e} k}=0\right)$ and a heat flux that is uniform over the domain, but oscillating in time $t$. Assuming constant salinity, the EOS for the surface density is $\rho_{1}=\overline{\rho_{1}}-\alpha T^{\prime}$, where $\overline{\rho_{1}}$ is the mean density, $\alpha$ is the thermal expansion coefficient appropriate at the mean temperature (i.e., a linearization is performed), and $T^{\prime}$ is the upper-layer temperature anomaly (e.g., associated with the annual cycle).

It follows directly from (5) that the thermocline depth remains constant across the domain at all times in this solution (i.e., $h=h_{\mathrm{e}}$ ), as shown in Fig. 7a. According to the linearized EOS and (6), the SSH anomaly associated with $T^{\prime}$ is given by

$$
\eta^{\prime}=\frac{\alpha T^{\prime} h_{\mathrm{e}}}{\rho_{2}} .
$$

Since temperature anomalies are zero initially, the uniform heating that we prescribe ensures that $T^{\prime}$ is also spatially uniform at all times. Assuming the same thermocline depth $\left(h_{\mathrm{e}}\right)$ and heat flux (i.e., $\left.T^{\prime}\right)$ in historical and future solutions, and neglecting changes in deep-ocean density $\left(\rho_{2}\right)$, it follows from (7) that changes in $\eta^{\prime}$ (e.g., the annual cycle range of sea level) are equal to changes in the $\alpha$ (i.e., the future change in sea level variability and the thermal expansion coefficient are equal). Figure $7 \mathrm{a}$ shows results for thermal expansion changes ranging from $-10 \%$ to $20 \%$, with $4.0 \%$ being the CMIP5 multi-model average increase in the subtropical North Pacific (Fig. 4a; domain average between $15^{\circ} \mathrm{N}-35^{\circ} \mathrm{N}$, $\left.120^{\circ} \mathrm{E}-120^{\circ} \mathrm{W}\right)$.

Case 2, oscillating wind forcing: densities remain constant in the second set of solutions (i.e., no oscillating heat forcing), however, the wind forcing is modulated in time according to $W_{e k}=W_{o}+W^{\prime} \cos t$, where $W_{o}$ and $W^{\prime}$ are the curl of the mean wind and the $y$-dependent amplitude of the time-varying wind, respectively. The frequency of the forcing $(\omega)$ is assumed to be sufficiently slow, such that the circulation remains near the Sverdrup balance; i.e., (5) holds at all times. The only effect of thermal expansion coefficient changes is that associated with the stratification change in $g^{\prime}$. Since $g^{\prime}$ occurs in the denominator of the forcing term in (5), it follows that for the same $W_{\mathrm{ek}}$, increased stratification is associated with a smaller slope of the future thermocline as well as reduced thermocline variability.

Supplementary Fig. 8 shows, for the historical and future climate conditions, the thermocline depth (i.e., surface-layer thickness, $h$ ) and SSH solutions when the wind forcing reaches its maximum strength (at $t=0)$ and the difference between that time and when minimum strength of the wind forcing occurs (at $t=\pi / \omega$ ). We set the wind forcing as follows: $W_{o}=0.5 \times 10^{-6} \mathrm{~m} \mathrm{~s}^{-1}$ and $W^{\prime}=0.1 \times W_{o}$. In all solutions, wind forcing causes the thermocline to be deep in the west and shallow in the east. In the future, with increased stratification and the associated reduction of the thermocline slope, and since the domain-integrated mass is conserved, the thermocline deepens in the east and shoals in the west. This weaker wind-forced mean response of the future thermocline (i.e., smaller slope) also translates to a reduced thermocline depth range $(\delta h)$ in the future relative to the historical solution (i.e., $\Delta \delta h<0$ ). Despite reduced thermocline variability, the historical and future SSH variability (i.e., range between strong and weak wind 
forcing) are nearly identical. This follows from the Sverdrup transports and mean thermocline depth being unchanged between historical and future solutions.

Figure $7 \mathrm{~b}$ shows the domain-average relative changes between the future and historical solutions for the variability of thermocline depth and SSH (i.e., the effect of CMIP5 projected stratification increase), as well as for a range of other stratification changes $(-10 \%$ to $20 \%)$ perceivable in past or future climates. For thermocline depth, the change is defined as $100 \times\left(\Delta|\partial h| / \overline{|\delta h|_{\text {historical }}}\right)$, which is the absolute value of the surface-layer thickness difference between strong and weak wind forcing (i.e., the thickness range) for the future minus historical solution, relative to the historical variability of such (Supplementary Fig. 8). The relative change for SSH is defined analogously, with surface-layer thickness replaced by SSH.

\section{Data availability}

The data that support the findings of this study are available from the Asia-Pacific DataResearch Center of the International Pacific Research Center (http://apdrc.soest.hawaii. edu), the University of Hawaii Sea Level Center (https://uhslc.soest.hawaii.edu/), and the Earth System Grid Federation (https://esgf-node.llnl.gov/projects/esgf-llnl/). Information about downloading the ORA-S5 SSH and ocean temperature data is available here: http:// apdrc.soest.hawaii.edu/datadoc/ecmwf_oras5_1 $1 \times 1$.php. The tide gauge data is available here: http://uhslc.soest.hawaii.edu/data/netcdf/rqds/atlantic/hourly/h755a.nc. The CMIP5 SSH data is available here: http://apdrc.soest.hawaii.edu/dods/public_data/ CMIP5/historical/zos. The CMIP5 ocean temperature data is available from the Earth System Grid Federation (linked above).

Received: 19 February 2020; Accepted: 26 June 2020;

Published online: 20 August 2020

\section{References}

1. Nerem, R. S. et al. Climate-change-driven accelerated sea-level rise detected in the altimeter era. Proc. Natl. Acad. Sci. U.S.A. 115, 2022-2025 (2018).

2. Wigley, T. M. L. \& Raper, S. C. B. Thermal expansion of sea water associated with global warming. Nature 330, 127-131 (1987).

3. Fasullo, J. T. \& Gent, P. R. On the relationship between regional ocean heat content and sea surface height. J. Clim. 30, 9195-9211 (2017).

4. Griffies, S. M. et al. An assessment of global and regional sea level for years 1993-2007 in a suite of interannual CORE-II simulations. Ocean Model. 78, 35-89 (2014).

5. Bindoff, N. L., Cheung, W. W. L. \& Kairo, J. G. in The Ocean and Cryosphere in a Changing Climate (ed Brad Seibel Manuel Barange) Ch. 5, 198 (IPCC, in press).

6. Oppenheimer, M. \& Glavovic, B. in The Ocean and Cryosphere in a Changing Climate (eds Ayako Abe-Ouchi, Kapil Gupta, \& Joy Pereira) Ch. 4, 169 (IPCC, in press).

7. Fasullo, J., Nerem, R. \& Hamlington, B. Is the detection of accelerated sea level rise imminent? Sci. Rep. 6, 31245 (2016)

8. Sweet, W. V. \& Park, J. From the extreme to the mean: acceleration and tipping points of coastal inundation from sea level rise. Earths Future 2, 579-600 (2014).

9. Moftakhari, H. R. et al. Increased nuisance flooding along the coasts of the United States due to sea level rise: Past and future. Geophys. Res. Lett. 42, 9846-9852 (2015).

10. Cazenave, A. \& Cozannet, G. L. Sea level rise and its coastal impacts. Earths Future 2, 15-34 (2014).

11. Vinogradov, S. V., Ponte, R. M., Heimbach, P. \& Wunsch, C. The mean seasonal cycle in sea level estimated from a data-constrained general circulation model. J. Geophys. Res. 113, C03032 (2008).

12. Piecuch, C. G. \& Ponte, R. M. Mechanisms of interannual steric sea level variability. Geophys. Res. Lett. 38, L15605 (2011).

13. Wyrtki, K. The slope of sea level along the equator during the 1982/1983 El Niño. J. Geophys. Res. 89, 10419-10424 (1984).

14. Merrifield, M. A., Kilonsky, B. \& Nakahara, S. Interannual sea level changes in the tropical Pacific associated with ENSO. Geophys. Res. Lett. 26, 3317-3320 (1999).

15. Widlansky, M. J., Timmermann, A., McGregor, S., Stuecker, M. F. \& Cai, W. An interhemispheric tropical sea level seesaw due to El Niño Taimasa. J. Clim. 27, 1070-1081 (2014).

16. Timmermann, A., McGregor, S. \& Jin, F. F. Wind effects on past and future regional sea level trends in the southern Indo-Pacific. J. Clim. 23, 4429-4437 (2010).

17. Long, $X$. et al. Higher sea levels at Hawaii caused by strong El Niño and weak trade winds. J. Clim. 33, 3037-3059 (2020).

18. Wang, B. et al. Historical change of El Niño properties sheds light on future changes of extreme El Niño. Proc. Natl. Acad. Sci. U.S.A. 116, 22512-22517 (2019).
19. Cai, W. et al. Increased variability of eastern Pacific El Niño under greenhouse warming. Nature 564, 201-206 (2018).

20. Cai, W. et al. Increased frequency of extreme La Niña events under greenhouse warming. Nature Clim. Change 5, 132-137 (2015).

21. Köhl, A. Detecting processes contributing to interannual halosteric and thermosteric sea level variability. J. Clim. 27, 2417-2426 (2014).

22. Yin, J., Griffies, S. M. \& Stouffer, R. J. Spatial variability of sea level rise in twenty-first century projections. J. Clim. 23, 4585-4607 (2010).

23. Widlansky, M. J., Timmermann, A. \& Cai, W. Future extreme sea level seesaws in the tropical Pacific. Sci. Adv 1, e1500560 (2015).

24. Barbosa, S. M., Silva, M. E. \& Fernandes, M. J. Changing seasonality in North Atlantic coastal sea level from the analysis of long tide gauge records. Tellus $A$ 60, 165-177 (2008).

25. Sweet, W. V. et al. In tide's way: Southeast Florida's September 2015 sunnyday flood. Bull. Amer. Meteor. Soc. 97, S25-S30 (2016).

26. Codiga, D. L. Unified Tidal Analysis and Prediction Using the UTide Matlab Functions, p. 59 (Graduate School of Oceanography, University of Rhode Island, Narragansett, RI, 2011).

27. Calafat, F. M., Wahl, T., Lindsten, F., Williams, J. \& Frajka-Williams, E. Coherent modulation of the sea-level annual cycle in the United States by Atlantic Rossby waves. Nat. Commun. 9, 2571 (2018).

28. Wahl, T., Jain, S., Bender, J., Meyers, S. D. \& Luther, M. E. Increasing risk of compound flooding from storm surge and rainfall for major US cities. Nat. Clim. Change 5, 1093-1097 (2015).

29. Rebert, J. P., Donguy, J. R., Eldin, G. \& Wyrtki, K. Relations between sea level, thermocline depth, heat content, and dynamic height in the tropical Pacific Ocean. J. Geophys. Res. 90, 11719-11725 (1985).

30. Gill, A. E. \& Niller, P. P. The theory of the seasonal variability in the ocean. Deep Sea Res. 20, 141-177 (1973).

31. Tsimplis, M. N. \& Woodworth, P. L. The global distribution of the seasonal sea level cycle calculated from coastal tide gauge data. J. Geophys. Res. 99, 16031-16039 (1994).

32. Vinogradova, N. T., Ponte, R. M. \& Stammer, D. Relation between sea level and bottom pressure and the vertical dependence of oceanic variability. Geophys. Res. Lett. 34, L03608 (2007).

33. IOC, SCOR \& IAPSO. The International Thermodynamic Equation Of Seawater-2010: Calculation and Use of Thermodynamic Properties. 196pp. (UNESCO, 2010)

34. Roquet, F., Madec, G., Brodeau, L. \& Nycander, J. Defining a simplified yet "realistic" equation of state for seawater. J. Phys. Oceanogr. 45, 2564-2579 (2015).

35. Ishii, M. et al. Accuracy of global upper ocean heat content estimation expected from present observational data sets. Sci. Online Lett. Atmosphere 13 163-167 (2017).

36. Domingues, C. M. et al. Improved estimates of upper-ocean warming and multi-decadal sea-level rise. Nature 453, 1090-1093 (2008).

37. Johnson, G. C., Schmidtko, S. \& Lyman, J. M. Relative contributions of temperature and salinity to seasonal mixed layer density changes and horizontal density gradients. J. Geophys. Res. Oceans 117, C04015 (2012).

38. Capotondi, A., Alexander, M. A., Bond, N. A., Curchitser, E. N. \& Scott, J. D. Enhanced upper ocean stratification with climate change in the CMIP3 models. J. Geophys. Res. Oceans 117, 23 (2012).

39. Michael, A. Alexander et al. Projected sea surface temperatures over the 21st century: Changes in the mean, variability and extremes for large marine ecosystem regions of Northern Oceans. Elem. Sci. Anth. 6, 9 (2018).

40. Bathiany, S., Dakos, V., Scheffer, M. \& Lenton, T. M. Climate models predict increasing temperature variability in poor countries. Sci. Adv. 4, eaar5809 (2018)

41. Thomas, M. D., Boer, A. M. D., Johnson, H. L. \& Stevens, D. P. Spatial and temporal scales of Sverdrup balance. J. Phys. Oceanogr. 44, 2644-2660 (2014).

42. Zuo, H., Balmaseda, M. A. \& Mogensen, K. The new eddy-permitting ORAP5 ocean reanalysis: description, evaluation and uncertainties in climate signals. Clim. Dyn. 49, 791-811 (2017).

43. Caldwell, P. C., Merrifield, M. A. \& Thompson, P. R. Sea level measured by tide gauges from global oceans-the Joint Archive for Sea Level holdings (NCEI Accession 0019568), Version 5.5, NOAA National Centers for Environmental Information, Dataset. https://doi.org/10.7289/V5V40S7W (2015).

44. Taylor, K. E., Stouffer, R. J. \& Meehl, G. A. An overview of CMIP5 and the experiment design. Bull. Amer. Meteor. Soc. 93, 485-498 (2012).

45. Olbers, D., Willebrand, J. \& Eden, C. Ocean Dynamics, p. 708 (Springer, 2012).

46. Roquet, F., Madec, G., McDougall, T. J. \& Barker, P. M. Accurate polynomial expressions for the density and specifc volume of seawater using the TEOS-10 standard. Ocean Model. 90, 29-43 (2015).

47. McDougall, T. J., Jackett, D. A., Wright, D. G. \& Feistel, R. Accurate and computationally efficient algorithm for potential temperature and density of seawater. J. Atmos. Oceanic Technol 20, 730-741 (2003).

48. Schloesser, F., Furue, R., McCreary, J. P. \& Timmermann, A. Dynamics of the Atlantic meridional overturning circulation. Part 2: Forcing by winds and buoyancy. Prog. Oceanogr. 120, 154-176 (2014). 
49. McCreary, J. P., Furue, R., Schloesser, F., Burkhardt, T. W. \& Nonaka, M. Dynamics of the Atlantic meridional overturning circulation and Southern Ocean in an ocean model of intermediate complexity. Prog. Oceanogr. 143, 46-81 (2016).

\section{Acknowledgements}

The authors acknowledge the World Climate Research Programme's Working Group on Coupled Modeling, which is responsible for CMIP, and we thank the climate modeling groups for producing and making available their model output. This work was primarily supported by NOAA grants NA17OAR4310110 and NA19OAR4310292. F.S. was supported by NSF grant 1558980 and NASA grant 80NSSC17K0564.

\section{Author contributions}

M.J.W wrote the paper. X.L. conducted the CMIP5 analysis. F.S. proposed the paper and determined the analytical solutions. All of the authors contributed to interpreting the results and editing the paper.

\section{Competing interests}

The authors declare no competing interests.
Correspondence and requests for materials should be addressed to M.J.W.

Peer review information Primary handling editor: Heike Langenberg.

Reprints and permission information is available at http://www.nature.com/reprints

Publisher's note Springer Nature remains neutral with regard to jurisdictional claims in published maps and institutional affiliations.

(c) (i) Open Access This article is licensed under a Creative Commons Attribution 4.0 International License, which permits use, sharing, adaptation, distribution and reproduction in any medium or format, as long as you give appropriate credit to the original author(s) and the source, provide a link to the Creative Commons license, and indicate if changes were made. The images or other third party material in this article are included in the article's Creative Commons license, unless indicated otherwise in a credit line to the material. If material is not included in the article's Creative Commons license and your intended use is not permitted by statutory regulation or exceeds the permitted use, you will need to obtain permission directly from the copyright holder. To view a copy of this license, visit http://creativecommons.org/ licenses/by/4.0\%.

\section{Additional information}

Supplementary information is available for this paper at https://doi.org/10.1038/s43247020-0008-8.
(C) The Author(s) 2020 